Repair in Guyon Canal. Microsurgery. 2012;32(4):296-302. doi:10.1002/micr.21951

4. S E Mackinnon. New directions in peripheral nerve surgery. Ann Plast Surg. 1989;22(3):257273. doi:10.1097/00000637-198903000-00013

5. Lee SK, Wolfe SW. Peripheral Nerve Injury and Repair. J Am Acad Orthop Surg. 2000;8(4):10.

6. M G Orgel. Epineurial versus perineurial repair of peripheral nerves. Clin Plast Surg. 1984;4:101-105.
7. Rowshan K, Jones NF, Gupta R. Current surgical techniques of peripheral nerve repair. Oper Tech Orthop. 2004;14(3):163-170. doi:10.1053/j.oto.2004.06.006

8. Kato H, Minami A, Kobayashi M, Takahara M, Ogino T. Functional results of low median and ulnar nerve repair with intraneural fascicular dissection and electrical fascicular orientation. ] Hand Surg. 1998;23(3):471-482. doi:10.1016/ S0363-5023(05)80465-4

\title{
KHẢO SÁT TÌNH HÌNH MẮC BÊNH LÝ MŨI XOANG VÀ MộT Số YẾU Tố LIÊN QUAN ĐẾN KHẢ NĂNG TIẾP CÂN CÁC DICH VỤ KHÁM CHỮA BỆNH BÊ̂NH LÝ VÙNG MŨI XOANG Ở BỀNH NHÂN TỪ 18 TUỔI TRỞ LÊN TẠI HUYỆN MỸ TÚ, TỈNH SÓC TRĂNG NĂM 2020 - 2021
}

\section{TÓM TẮT}

Mục tiêu: Xác định tỷ lệ mắc các bệnh lý mũi xoang và khả năng tiếp cân các dịch vụ khám chữa bệnh ở bệnh nhân từ 18 tuổi trở lên mắc bệnh lý vùng mũi xoang tại Huyên Mỹ Tú, Tỉnh Sóc Trăng, năm 2020 -2021. Đối tượng và phương pháp: Nghiên cứu mô tả cắt ngang trên 640 người dân từ 18 tuổi trở lên tại Huyện Mỹ Tú, Tỉnh Sóc Trăng từ tháng 512/2020. Kểt quả: Tỷ lệ mắc bệnh lý vùng mũi xoang là $27,5 \%$. Trong đó, bệnh viêm mũi dị ứng là 44,9\%, viêm mũi xoang cấp tính là $20,5 \%$, viêm mũi xoang mạn tính là $33,5 \%$, Polype mũi là $1,1 \%$. $75 \%$ ở mức đồ nhe. . Tỷ lế đối tướng nghiên cứu tiếp cân dich vu khám chữa bệnh các bệnh lý mũi xoang là $77,3 \%$. Yếu tố liên quan đến tỷ lệ tiếp cận các dịch vu khám chữa bệnh của người dân bao gồm: Nơi ở, khoảng cách đến CSYT gần nhất, mức độ mắc bệnh, loại hình bệnh mũi xoang. Kết luận: Tỷ lệ mắc bệnh mũi xoang tại huyên Mỹ Tú, tỉnh Sóc Trăng khá cao chiếm $27.5 \%$ số đối tượng tham gia nghiên cứu. Khả năng tiếp cận các dịch vu khám chữa bệnh liên quan đến nơi ở, khoảng cách đến cơ sở y tế gần nhất, mức độ mắc bệnh, loại hình bênh mũi xoang.

Tứ khóa: Bênh lý mũi xoang, tiếp cận dịch vụ khám chữa bệnh, dịch vụ y tế.

\section{SUMMARY \\ INVESTIGATING DISEASES RELATED TO SINONASAL REGION AND EVALUATING ASSOCIATING FACTORS THAT EFFECT THE ACCESSIBILITY OF ADULT PATIENTS TO APPROPRIATE TREATMENTS AT MY TU}

${ }^{1}$ Trường đại học Y dược Cần Tho

²Bênh viện Đa khoa Tỉnh Sóc Trăng

Chịu trách nhiệm chính: Nguyễn Triều Việt

Email: vietctho@gmail.com

Ngày nhận bài: 2/8/2021

Ngày phản biên khoa học: 25/8/2021

Ngày duyệt bài: 24/9/2021

\section{Nguyễn Triều Việt ${ }^{1}$, Triệu Sà Kinh ${ }^{2}$}

DISTRICT, SOC TRANG PROVINCE, 2020-2021

Objectives: to determine the prevalence of sinonasal diseases and to evaluate associating factors effecting the accessibility of adult patients to appropriate treatments at My Tu district, Soc Trang province, 2020-2021. Subjects and methods: A cross-sectional study was conducted from over 640 people aged 18 years and older in My Tu district, Soc Trang province. Results: The prevalence of diseases of nose and paranasal sinuses is $27,5 \%$. Among those diseaseas, allergic rhinitis made up the largest proportion with $44,9 \%$. The percentages of chronic rhinitis, acute rhiniti, nasal polyposis accounted for $33,5 \%, 20,5 \%, 1,1 \%$ respectively. $75 \%$ out of all patients was not in severe conditions. The figure of study subjects accessing medical examination and treatment services for nose and sinus diseases was $77,3 \%$. Associating factors effecting the accessibility of patients to appropriate treatments are: place of residence, distance to the closet health facilities, types and severity of mentioned disorders. Conclusions: The prevalence of sinonasal diseases is significantly high in conducted location. In the coming years, the goverment of Soc Trang province needs to enact policies increasing the accessibility of people to local heathcare systems, ensuring the availability of appropriate healthcare services and strengthening communication methods of health education to raise people's understanding about the mentioned diseases.

Keywords: Diseases of the nose and sinuses, accessing medical examination and treatment services, health services.

\section{I. ĐẶT VẤN ĐỀ}

Các bệnh lý tai mũi họng khá phổ biến ở nước ta, ảnh hưởng đến sức khỏe. Các yếu tố ảnh hương tới bệnh lý TMH bao gồm kinh tế chậm phát triển, vệ sinh môi trường kém, nước thải, rác thải không được xử lý. Ô nhiếm môi trường, lao động nặng nhọc trong điều kiện chưa đảm bảo. Những thay đổi về vi khí hậu nơi ở, nơi làm 
việc có ảnh hưởng lớn đến sức khỏe và năng suất lao động, gây các bệnh theo mùa, thời tiết [3].

Quá trình biến đổi mạnh mẽ về điều kiện kinh tế, xã hội và môi trường tại các khu vực đô thị cũng tạo ra nhiều thách thức đối với hệ thống y tế như: Chính sách y tế và năng lực hệ thống y tế cơ sở tại các khu vực đô thị chưa đáp ứng được nhu cầu chăm sóc sức khỏe (CSSK) của người dân. Ở Việt Nam, đã có nghiên cứu so sánh tình hình sức khỏe của người dân sống ở khu vực đô thị và khu vực nông thôn, cho thấy người dân ở khu vực nông thôn có tình trạng sức khỏe và khả năng tiếp cận dịch vụ y tế rất hạn chế; tỷ lệ khám chữa bệnh (KCB) ở thành thị cao hơn nông thôn. Nhiều người dân đã rơi vào cảnh vay mượn, nợ nần do chi tiêu cho khám chữa bệnh, trong đó tỷ lệ này đối với người dân ở nồng thôn luôn cao hơnn so với thành thị [8]. Nếu viêm mũi di ứng (VMDƯ') thường xuyên xảy ra ở trẻ em thì các bệnh như: viêm mũi xoang cấp và mạn tính, polype mũi, lệch vách ngăn cũng như là khối u vùng mũi xoang lại xảy ra chủ yếu ở người lớn. Tuy nhiên với sự chủ quan và phần lớn thời gian dành cho công việc nên người lớn thường không được tiếp cận các DVKCB so với trẻ em.

Để cung cấp các bằng chứng khoa học hỗ trợ các nhà quản lý trong quá trình xây dựng các chính sách và can thiệp nhằm cải thiện tình trạng sức khỏe, nâng cao khả năng tiếp cận và giảm thiểu gánh nặng chi tiêu cho các DVKCB của người dân, chúng tôi tiến hành "Nghiên cứu tình hình mắc bệnh, khả năng tiếp cận các dịch vụ khám chữa bệnh và một số yếu tố liên quan khả năng tiếp cận các DVKCB ở bệnh nhân từ 18 tuổi trở lên mắc bệnh lý vùng mũi xoang (VMX) tại Huyện Mỹ Tú, Tỉnh Sóc Trăng, năm 2020 -2021" với các mục tiêu:

- Xác đ̛̣inh tỷ lê mắc một số bệnh mũi xoang thường gặp ở bệnh nhân 18 tuổi trở lên tại huyện Mỹ Tú, tỉnh Sóc Trăng năm 2020-2021.

- Xác định khả năng tiếp cận và một số yêu tố liên quan đến khả năng tiếp cận các DVKCB các bệnh lý vùng mũi xoang tại huyện Mỹ Tú, tỉnh Sóc Trăng năm 2020 - 2021.

\section{II. ĐỐI TƯợNG VÀ PHƯƠNG PHÁP NGHIÊN CỨU}

2.1. Đối tượng nghiên cứu: Người dân từ đủ 18 tuổi trở lển hiện đang sinh sống tại huyện Mỹ Tú, tỉnh Sóc Trăng.

Tiêuu chuẩn chọn mẫu: Đối tượng từ đủ 18 tuổi trở lên có hộ khẩu thường trú tại huyện Mỹ Tú, Tỉnh Sóc Trăng hoặc cư trú > 12 tháng trong thời điểm nghiên cứu, có khả năng nghe hiểu, trả lời phỏng vấn và đồng ý tham gia nghiên cứu.

Tiêu chuẩn loại trừ: Những đối tượng vắng mặt cả 3 lần thu thập thông tin; những người đang mắc các bệnh nặng không đi lại được; những người mắc các bệnh hạn chế khả năng giao tiếp như tâm thần; những người từ chối tham gia nghiên cứu.

2.2. Phương pháp nghiên cứu: sử dụng thiết kế nghiên cứu mô tả cắt ngang có phân tích. Chọn 640 đối tượng nghiên cứu bằng phương pháp chọn mẫu nhiều giai đoạn.

Giai đoạn 1: Tại huyện Mỹ Tú có 1 thị trấn và 10 xã. Chúng tôi chọn 1 thị trấn Huỳnh Hữu Nghĩa và chọn ngẫu nhiên 4 xã vào nghiên cứu. Mấu nghiên cứu cần là 640 chia đều cho 5 xã/Thị trấn, vậy mỗi xã/Thị trấn cần 120-130 người.

Giai đoạn 2: Các xã/Thị trấn từ giai đoạn 1, chọn ngẫu nhiên 2 Ấp/Phường. Tại mối ấp sẽ lấy 60-65 đối tượng.

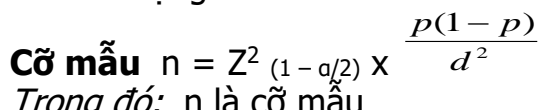

Trong đó: $\mathrm{n}$ là cõ mâu

- $Z_{(1-a / 2)}$ : hệ số tin cậy. Với độ tin cậy $95 \%$, ta có $Z_{(1-\mathrm{a} / 2)}=1,96$.

- p: tỷ lệ mắc bệnh lý VMX tại cộng đồng. Theo nghiên cứu của Phùng Minh Lương (2011) tỷ lệ mắc bệnh mũi xoang tại cộng đồng là 40,3\% [7]. Chọn $p=0,4$.

- $d$ : sai số mong muốn. Chọn $d=0,05$.

Thay vào công thức được cỡ mẫu là 369 bệnh nhân. Vì có sử dụng phương pháp chọn mẫu cụm nên để giảm sai số, $\mathrm{n}$ được nhân với hiệu ứng thiết kế $D E=1.5$. Để dự phòng mất mẩu chúng tôi tăng thêm $15 \%$ mẫu. Vậy cỡ mẫu cần thiết là 636, chúng tôi làm tròn 640 người.

Các đối tương nghiên cứu mắc bệnh lý vùng mũi xoang từ mục tiêu 1 được đưa vào nghiên cứu cho mục tiêu 2.

\section{Nội dung nghiên cứu:}

- Đặc điểm chung: Tuổi, giới, nghề nghiệp, trình độ học vấn, dân tộc, nơi ở, kinh tế, khoảng cách đển CSYT gần nhất.

- Tình hình mắc bệnh lý mũi xoang: Được xác định có mắc bệnh lý VMX khi đối tượng có mắc ít nhất một bệnh lý VMX như: viêm mũi dị ứng, viêm xoang cấp, viêm xoang mạn, polype mũi, lệch vách ngăn, các khối u VMX.

- Tiếp cận các DVKCB: Có khi đối tượng nghiên cứu có đến CSYT khi mắc bệnh VMX. Các trường hợp tự mua thuốc và không điều trị được tính là khônng có tiếp cận DVKCB.

- Một số yếu tố liển quan tiếp cận DVKCB: Đặc điểm chung, loại hình bệnh mắc phải, mức độ mắc bệnh. 
Phương pháp thu thập số liệu: Phỏng vấn trực tiếp bộ câu hỏi.

Phương pháp xử lý số liệu: Phần mềm SPSS 26.0

\section{KẾT QUẢ NGHIÊN CỨU}

\subsection{Thông tin chung}

Bảng 1. Đặc điểm chung của đối tượng nghiên cứu

\begin{tabular}{|c|c|c|c|c|c|c|c|}
\hline & ến số & Tân số & Tỷ lệ & & Biến số & Tân số & Tỷ lệ \\
\hline Gióói & Nam & 231 & 36,1 & & Kinh & 317 & 49,5 \\
\hline GlOI & Nũ̃ & 409 & 63,9 & Dân tôn & Hoa & 7 & 1,1 \\
\hline & 18-40 tuổi & 229 & 35,8 & Dart tộ & Khmer & 316 & 49.4 \\
\hline Tuô̂i & 41-60 tuối & 265 & 41,4 & & NIIIIET & & \\
\hline & $>60$ tuô̂i & 146 & 22,8 & Kinh tế & Nghèo-cận nghèo & 106 & 16,6 \\
\hline & Mù chữ & 68 & 10,6 & & & & \\
\hline & Tiếu học & 198 & 30,9 & & Không nahèo & 534 & 834 \\
\hline vấn & THCS & 228 & 35,6 & & & & \\
\hline & THPT & 97 & 15,2 & & Thành thi & 19 & 3,0 \\
\hline & $\begin{array}{c}\text { > THPT } \\
\text { HSSV }\end{array}$ & $\frac{49}{4}$ & $\begin{array}{l}7,7 \\
0,6\end{array}$ & Nơi ở & & & \\
\hline & Nông dân & 40 & 6,3 & & Nông thôn & 621 & 97,0 \\
\hline & $\mathrm{CBCC}, \mathrm{VC}$ & 41 & 6,4 & & & & \\
\hline & Buôn bán & 270 & 42,2 & & $<5 \mathrm{~km}$ & 518 & 80,9 \\
\hline Nghề & Công nhân & 106 & 16,6 & CSYT & & & \\
\hline nghiệp & Nội trợ & 131 & 20,5 & gần nhất & $\geq 5 \mathrm{~km}$ & 122 & 19,1 \\
\hline & Khác & 48 & 7,5 & & & & \\
\hline 1,4 & Trong & & 1 & & $\begin{array}{l}\text { Không } \\
\text { Tống }\end{array}$ & $\begin{array}{l}40 \\
76\end{array}$ & $\begin{array}{r}22,7 \\
1000\end{array}$ \\
\hline
\end{tabular}

tỷ lệ cao nhất $(42,2 \%)$. Trình đô THCS chiếm tỷ lê cao nhất $(35,6 \%)$. tỷ lê đối tượng nghiên cứu dân tộc Kinh và dân tộc Khmer là gần như nhau (49,5\% và 49,4\%); $16,6 \%$ đối tượng nghiên cứu thuộc diên nghèo, cân nghèo; $97 \%$ đối tượng nghiên cứu ở nông thôn; $19,1 \%$ đối tượng nghiên cứu có khoảng cách đến CSYT gần nhất $\geq 5 \mathrm{~km}$.

Bảng 2. Tỉnh hinh mắc bệnh lý mũi xoang

\begin{tabular}{|c|c|c|}
\hline $\begin{array}{c}\text { Tiếp cận dịch vụ } \\
\mathbf{y} \text { tế }\end{array}$ & Tân số (n) & $\begin{array}{c}\text { Tỷ lệ } \\
\text { (\%) }\end{array}$ \\
\hline Có & 136 & 77,3 \\
\hline
\end{tabular}

Nhân xét: Trong nghiên cứu, 27,5\% đối tượng mắc bệnh VMX.

Bảng 3. Tình hinh tiếp cận các dịch vụ y tế khám chữa bênh

\begin{tabular}{|c|c|c|}
\hline Tiếp cận dịch vụ y tế & Tân số(n) & Tỷ lệ(\%) \\
\hline Có & 136 & 77,3 \\
\hline Không & 40 & 22,7 \\
\hline Tống & $\mathbf{1 7 6}$ & $\mathbf{1 0 0 , 0}$ \\
\hline
\end{tabular}

Nhận xét: Trong nghiên cứu, tỷ lệ đối tượng nghiên cứu có tiếp cận dịch vụ khám chữa bệnh là $77,3 \%$.

\subsection{Các yếu tố liên quan đến sử dụng dịch vư y tế khám chữa bệnh mưi xoang}

Bảng 4. Liên quan giữa sử dụng DVKCB và đặc điểm chung

\begin{tabular}{|c|c|c|c|c|c|c|c|}
\hline \multirow{2}{*}{ Biến số } & \multirow{2}{*}{ Đơn vị } & \multicolumn{2}{|c|}{ Có } & \multicolumn{2}{|c|}{ Không } & \multirow{2}{*}{$\begin{array}{c}\text { OR } \\
\text { (KTC 95\%) } \\
\end{array}$} & \multirow{2}{*}{$\mathbf{P}$} \\
\hline & & $\mathbf{n}$ & $\%$ & $\mathbf{n}$ & $\%$ & & \\
\hline \multirow{2}{*}{ Giới tính } & Nam & 40 & 76,9 & 12 & 23,1 & \multirow{2}{*}{$0,972(0,450-2,100)$} & \multirow{2}{*}{0,943} \\
\hline & Nữ & 96 & 77,4 & 28 & 22,6 & & \\
\hline \multirow{3}{*}{ Nhóm tuổi } & 18-40 tuối & 37 & 72,5 & 14 & 27,5 & 1 & - \\
\hline & 40-60 tuối & 66 & 77,6 & 19 & 22,4 & $0,761(0,343-1,692)$ & 0,503 \\
\hline & $>60$ tuối & 33 & 82,5 & 7 & 17,5 & $0,561(0,202-1,557)$ & 0,267 \\
\hline \multirow{2}{*}{ Dân tộc } & Kinh - Hoa & 68 & 82,9 & 14 & 17,5 & \multirow{2}{*}{$1.857(0,894-3,860)$} & \multirow{2}{*}{0,095} \\
\hline & Khmer & 68 & 72,3 & 26 & 27,7 & & \\
\hline \multirow{5}{*}{$\begin{array}{c}\text { Trình độ học } \\
\text { vấn }\end{array}$} & Mù chữ & 19 & 79,2 & 5 & 20,8 & 1 & - \\
\hline & Tiếu học & 37 & 71,2 & 15 & 28,8 & $1,541(0,486-4,882)$ & 0,463 \\
\hline & THCS & 55 & 85,9 & 9 & 14,1 & $0,622(0,185-2,088)$ & 0,442 \\
\hline & THPT & 14 & 63,6 & 8 & 36,4 & $2,171(0,584-8,075)$ & 0,247 \\
\hline & $>$ THPT & 11 & 78,6 & 3 & 21,4 & $1,036(0,207-5,198)$ & 0,965 \\
\hline
\end{tabular}




\begin{tabular}{|c|c|c|c|c|c|c|c|}
\hline \multirow{6}{*}{ Nghề nghiệp } & CBVC & 13 & 92,9 & 1 & 7,1 & 1 & 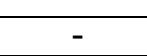 \\
\hline & Công nhân & 7 & 87,5 & 1 & 12,5 & $1,857(0,100-34,439)$ & 0,678 \\
\hline & Nông dân & 56 & 70,0 & 24 & 30,0 & $5,57(0,690-45,018)$ & 0,107 \\
\hline & Buôn bán & 26 & 89,7 & 3 & 10,3 & $1,500(0,142-15,872)$ & 0,736 \\
\hline & Nội trợ & 29 & 78,4 & 8 & 21,6 & $3,586(0,406-31,704)$ & 0,251 \\
\hline & Khác & 5 & 62,5 & 3 & 37,5 & $7,800(0,649-93,807)$ & 0,106 \\
\hline \multirow{2}{*}{ Kinh tế } & Nghèo-cận nghèo & 24 & 70,6 & 10 & 29,4 & \multirow[b]{2}{*}{$0,643(0,277-1,490)$} & \multirow[b]{2}{*}{0,3} \\
\hline & Không nghèo & 112 & 78,9 & 30 & 21,1 & & \\
\hline \multirow{2}{*}{ Nơi ở } & Thành thị & 1 & 25,0 & 3 & 75,0 & \multirow{2}{*}{$0,091(0,009-0,904)$} & \multirow{2}{*}{0,037} \\
\hline & Nông thôn & 135 & 78,5 & 37 & 21,5 & & \\
\hline \multirow{2}{*}{$\begin{array}{l}\text { Khoảng cách } \\
\text { đến CSYT }\end{array}$} & $<5 \mathrm{~km}$ & 122 & 83,6 & 24 & 16,4 & \multirow{2}{*}{$5,810(2,507-13,460)$} & \multirow{2}{*}{$<0,001$} \\
\hline & $\geq 5 \mathrm{~km}$ & 14 & 46,7 & 16 & 53,3 & & \\
\hline
\end{tabular}

Nhận xét: Tỷ lệ tiếp cận DVKCB ở nhóm thành thị là $25 \%$, nhóm nông thôn là $78,5 \%$. Tỷ số chênh là 0,091(KTC 95\%: 0,009-0,904). Tỷ lệ tiếp cận DVKCB ở nhóm có khoảng cách đến CSYT < $5 \mathrm{~km}$ là $83,6 \%$, nhóm $\geq 5 \mathrm{~km}$ là 46,7\%. Tỷ số chênh là 5,810 (KTC 95\%: 2,507-13,460). Sự khác biệt có ý nghĩa thống kê.

Bảng 5. Liên quan giữa sử dụng DVKCB và mức độ mắc bệnh

\begin{tabular}{|c|c|c|c|c|c|c|c|}
\hline \multirow{2}{*}{ Biến số } & \multirow{2}{*}{ Loại bệnh lý } & \multicolumn{2}{|c|}{ Có } & \multicolumn{2}{|c|}{ Khống } & \multirow{2}{*}{$\begin{array}{c}\text { OR } \\
\text { (KTC 95\%) } \\
\end{array}$} & \multirow[b]{2}{*}{$\mathbf{p}$} \\
\hline & & $\mathbf{n}$ & $\%$ & $\mathbf{n}$ & $\%$ & & \\
\hline \multirow{4}{*}{$\begin{array}{l}\text { Loai bệnh } \\
\text { mắc phải }\end{array}$} & VMDU & 49 & 62,0 & 30 & 38,0 & 1 & - \\
\hline & VMX cấp tính & 30 & 83,3 & 6 & 16,7 & $0,327(0,122-0,877)$ & 0,026 \\
\hline & VMX mạn tính & 55 & 93,2 & 4 & 6,8 & $0,119(0,039-0,361)$ & 0,000 \\
\hline & Polype mũi & 2 & 100 & 0 & 0,0 & - & 0,999 \\
\hline \multirow{2}{*}{ Mức độ } & Nhe & 95 & 72,0 & 37 & 28,0 & \multirow[t]{2}{*}{$0,188(0,055-0,644)$} & \multirow{2}{*}{0,002} \\
\hline & Vừa-nặng & 41 & 93,2 & 3 & 6,8 & & \\
\hline
\end{tabular}

Nhận xét: Tỷ lệ tiếp cận DVKCB ở nhóm bệnh viêm mũi di ứng là $62,0 \%$, nhóm VMX cấp tính là $83,3 \%$, VMX mạn tính là 93,2\%, polype mũi là $100 \%$. Tỷ lệ tiếp cận DVKCB ở nhóm nhẹ là $72,0 \%$, nhóm có mức độ bệnh từ vừa đến nặng là $93,2 \%$. Sự khác biệt ghi nhận ý nghĩa thống kê $(p<0,05)$.

\section{BÀN LUẬN}

4.1. Thông tin chung. Trong nghiên cứu, 63,9\% đối tượng nghiên cứu là nữ và chỉ $36,1 \%$ đối tượng nghiên cứu là nam. Phần lớn đối tượng nghiên cứu trong độ tuổi 40-60 tuổi. Có $41,4 \%$ đối tượng nghiên cứu từ 41-60 tuổi, tiếp đến là nhóm 18-40 tuổi chiếm tỷ lệ $35,8 \%$ và cuối cùng là nhóm >60 tuổi chiếm tỷ lệ đến 22,8\%. Tỷ lệ đối tượng nghiên cứu dân tộc Kinh và Khmer là gần như bằng nhau với tỷ lệ lần lượt là $49,5 \%$ và $49,4 \%$; chỉ $1,1 \%$ đối tượng nghiên cứu là dân tộc Hoa. Nghiên cứu cưa chúng tôi tương tự với nghiên cứu của Nguyễn Hồng Đạo và cS (2016) với tỷ lệ dân tộc Kinh tỏng nghiển cứu là $24,8 \%$, còn lại là dân tộc khác [3].

Tỷ lệ đối tượng nghiên cứu có trình độ THCS chiếm tỷ lệ cao nhất $(35,6 \%)$, tiếp đến là trình độ Tiểu học 30,9\%. Chỉ 7,7\% đối tượng nghiên cứu có trình độ học vấn trên THPT. Qua đây, có thể thấy rằng trình độ dân trí của địa bàn nghiên cứu nằm ở mức trung bình vì phần lớn đối tượng nghiên cứu có trình độ tiểu học và THCS, chỉ một số ít có trình độ trên THPT. Gần đến một nửa đối tượng nghiên cứu là nông dân (42,2\%). Ngoài ra với $63,9 \%$ đối tượng nghiên cứu là nữ thì trong nghiên cứu của chúng tôi có đến 20,5\% đối tượng nghiên cứu là nội trợ và gần 7,5\% đối tượng nghiên cứu là người già, hưu trí vì nghiên cứu có đến $22,8 \%$ đối tượng nghiên cứu là người trên 60 tuổi. Kết quả nghiên cứu của chúng tôi tương tự nghiên cứu của Trần Thị Kim Lý (2008) với tỷ lệ đối tượng nghiên cứu có trình độ $\mathrm{TH}$ và THCS là $61,29 \%$ [6]. Chỉ 3,0\% đối tượng nghiên cứu ở khu vực thành thị. Vẫn còn $16,6 \%$ đối tượng nghiên cứu thuộc diện nghèo, cận nghèo. Nghiên cứu của chúng tôi có sự khác biệt với nghiên cứu của Trương Việt Dũng và cs (2003) với tỷ lệ đối tượng nghiên cứu thuộc diện nghèo chiếm $4,8 \%$. Sự khác biệt là do sự khác nhau về địa bàn nghiên cứu.

4.2. Tình hình mắc bệnh lý viêm mũi xoang. Trong nghiên cứu, 27,5\% đối tượng nghiên cứu mắc bệnh TMH. Trong đó, đối tượng nghiên cứu bị viêm mũi dị ứng là $44,9 \%$, viêm mũi xoang cấp tính là $20,5 \%$, viêm mũi xoang mạn tính là 33,5\%, Polype mũi là $1,1 \%$. $75 \%$ đối tượng nghiên cứu bị bệnh ở mức độ nhẹ, 15,9\% đối tượng nghiên cứu bị mức độ vừa và chỉ $9,1 \%$ đối tượng nghiên cứu bị mức độ nặng. Do phần lớn bệnh trong nghiên cứu của chúng tôi là viêm mũi dị ứng nên mức độ bị bệnh phần lớn nằm ở 
mức nhẹ. Theo nghiên cứu của Lê Thị Thanh Hoa (2018) với tỷ lệ bệnh viêm mũi xoang ở công nhân tương tự nghiên cứu của chúng tôi là 23,18\%[4]. Nghiên cứu của Đỗ Đức Huy cũng cho kết quả tương tự với 30,0\% đối tượng nghiên cứu bị mắc bệnh lý mũi xoang [5].

4.3. Các yếu tố liên quan đến tiếp cân dịch vụ khám chữa bệnh (DVKCB). Theo nghiên cứu của chúng tôi thì tỷ lệ tiếp cận và sử dụng DVKCB ở thành thị lại thấp hơn nông thôn. Tỷ lê tiếp cân DVKCB ở nhóm thành thi là $25 \%$, nhóm nông thôn là $78,5 \%$. Tỷ số chênh là 0,091 (KTC 95\%: 0,009-0,904). Sự khác biệt ghi nhận ý nghiã thống kê. Sự khác biệt này có thể là do những đối tượng sống tại thành thi có nhiều cơ hội tiếp cậm với dịch vư khám chữa bênh công và tư, cũng như nhiều hình thức chữa bệnh khác nhau. Cùng với mức sống cao hơn là nhịp điệu cuộc sống ở thành thi nhanh và nhôn nhip hớn so với nông thôn. Thêm vào là những bệnh lý VMX trong nghiên cứu ở mức nhẹ nên đối tượng có xu hướng chủ quan, không điều trị hoặc đến các quây thuốc tây tìm mua thuốc điều trị nhanh chóng và tiết kiệm thời gian hơn.

Nghiên cứu ghi nhận tỷ lệ tiếp cận và sử dụng DVKCB ở nhóm có khoảng cách đến CSYT $<5 \mathrm{~km}$ là $83,6 \%$, nhóm $\geq 5 \mathrm{~km}$ là $46,7 \%$. Tỷ số chênh là 5,810 (KTC 95\%: 2,507-13,460). Sự khác biệt có ý nghĩa thống kê.

Nghiên cứu cho thấy, đối tượng nghiên cứu bị viêm mũi dị ứng là $44,9 \%$ và $75 \%$ đối tượng nghiên cứu bị bệnh ở mức độ nhẹ. Nghiên cứu ghi nhận mối liên quan giữa loại bệnh mắc phải cũng như mức độ bệnh với khả năng tiếp cận, sử dung DVKCB của đối tượng nghiên cứu. Tỷ lê tiếp cận $\mathrm{DVKCB}$ ở nhóm bệnh viêm mũi dị ứng là 62,0\%, nhóm VMX cấp tính là 83,3\%, VMX mạn tính là $93,2 \%$, polype mũi là $100 \%$. Tỷ số chênh chỉ ra sự khác biệt giữa tỷ lệ sử dụng DVKCB ở nhóm viêm mũi dị ứng và nhóm viêm mũi xoang cấp tính là $\mathrm{OR}=0,327$ (KTC 95\%: 0,122-0,877); nhóm viêm mũi xoang mạn tính $\mathrm{OR}=0,119$ (KTC 95\%: 0,039-0,361). Sự khác biệt ghi nhận ý nghĩa thống kê.

Về mức độ, những đối tượng nghiên cứu có bệnh nhẹ có xu hướng chủ quan hơn bệnh nặng nển tỷ lệ tiếp cận, sử dụng DVKCB ở nhóm bệnh nhe thấp hơn nhóm bểnh vừa và nặng. Tỷ số chênh $\mathrm{OR}=0,188$ (KTC 95\%: 0,055-0,644). Sự khác biệt ghi nhận ý nghĩa thống kê với $p=0,002$. Vì vậy, nâng cao tính tự giác trong việc đến khám, chữa bệnh khi bị ốm đau và người dân được tiếp cận, hưởng thụ các dịch vụ khám chữa bệnh, góp phần cải thiện sức khỏe, thể lực là hết sức cần thiết.

\section{KẾT LUẬN}

- Tỷ lệ mắc bênh mũi xoang: $27,5 \%$ đối tượng mắc bệnh VMX. Bệnh viêm mũi dị ứng là $44,9 \%$, viêm mũi xoang cấp tính là $20,5 \%$, viêm mũi xoang mạn tính là $33,5 \%$, Polype mũi là $1,1 \% .75 \%$ ở mức đô nhe.

- Tỷ lệ tiếp cận DVKCB: tỷ lệ đối tượng nghiên cứu có tiếp cận dịch vụ khám chữa bệnh là $77,3 \%$.

- Yếu tố liên quan khả năng tiếp cận DVKCB:

+ Tỷ lệ tiếp cận DVKCB ở nhóm thành thị thấp hơn nhóm nông thôn.

+ Tỷ lệ tiếp cận và sử dụng DVKCB ở nhóm có khoảng cách đến CSYT $<5 \mathrm{~km}$ là cao hơn nhóm $\geq 5 \mathrm{~km}$.

+ Tỷ lệ tiếp cận DVKCB ở nhóm bệnh viêm mũi di ứng thấp hơnn nhóm mắc bệnh VMX mạn tính và VMX cấp tính.

+ Tỷ lệ tiếp cận DVKCB ở nhóm bệnh nhẹ thấp hơn nhóm bệnh vừa và nặng.

\section{TÀI LIÊU THAM KHẢO}

1. Bênh viện Tai Mũi Hộng Sài Gòn, Tổng hợp về giải phấu sinh lỹ mũi xoang và bệnh viêm mũi xoang.

2. Trương Việt Dũng và cs (2003), Nghiên cứu nhu cầu và sử dung dịch vu khám chữa bênh tai nội thành Hà Nội, Tạp chí Nighiên cứu y học, 26 (6), 2003, trang 115-i21.

3. Nguyễn Hồng Đạo và cs (2016), Nhu cầu và khả năng tiếp cận dịch vụ y tế của người khuyết tật do seo di chứng bỏng tai 3 tînh Hà Giang, Lai Châu, Điện Biên, Tạp chí Ý học Thực hành số 5 năm 2016 .

4. Lê Thị Thanh Hoa (2018), Thực trạng các bệnh hộ hấp và kết quả một số giải pháp can thiệp ở cổng nhân khai thác than mỡ taai Thái Nguyên, Báo cóa tổng kết Đề tài Khoa học và công nghiệp cấp Đai hoc, Trường Đai hoc $Y$ dược Thái Nguyên.

5. Đồ Đức Huy (2015), Thực trang bệnh Tai Mũi Hong, yếu tố liên quan ở người lao đồng sản xuất gổm tại làng nghề Phù Lãng - Quế Võ- Bắc Ninh, Tạp chí Tai Mũi Họng Việt Nam, vol 60-28, No 4, 2015, trang 75-82.

6. Trân Thị Kim Lý (2008), Nghiên cứu tình hình sử dụng dịch vụ khám chứa bênh của người dân tại xã IaKhuoi, xã IaPhi, xã Hịa Phú, huyện Chuwpah, tỉnh Gia Lai, Luận văn tốt nghiệp chuyển khoa cấp 1, Trường Đại học $Y$ dược Huế.

7. Phùng Minh Lương (2011), Nghiên cứu mô hình và các yếu tố ảnh hưởng đên bênh Tai Mũi Hong thông thường của dân tộc Ê Đê Tây Nguyên, Đảnh giá kết quả của một số biện pháp can thiệp phù hợp ở tuyến bản, Luận văn tốt nghiệp Tiến sĩ Y hoc, Trường Đai học Y dược Hà Nôi.

8. Lê Thân Tuấn (2013), Tình hình ốm đau, và Ốm đau, sử dụng và chi tiêu cho dịch vụ khám chữa bênh của người dân ở môt số khu vức thuộc nội thành Hà Nội, Luận án tốt nghiệp Tiến sĩ, Trường Đại học Y Hà Nội. 